DOI: 10.20472/IAC.2018.036.049

\author{
ASHWINI TIWARI \\ University of Houston-Downtown, United States
}

\title{
MEASURING GENERAL EDUCATION TEACHERS' ATTITUDES AND PERCEPTION TOWARDS INCLUSION OF SPECIAL EDUCATION STUDENTS.
}

\begin{abstract}
:
The purpose of this interpretive research was to understand the perspectives and beliefs of pre-service teachers enrolled at one of the public state universities in Texas, USA toward including students with disabilities in regular education classrooms. Employing hermeneutic phenomenology as methodological framework, this study used 20 semi-structured interviews and 5 focus groups as data sources. Initial data analysis was done using NVivo software. Themes were created based on the initial data analysis. This study revealed that teachers viewed inclusive education practices as pedagogically challenging. However, teacher candidates who chose to work with people with disabilities as their service learning assignment have more favorable attitudes towards students with disabilities. This paper will discuss the implications for service learning component for pre-service general education teachers. Furthermore, this paper will offer suggestions for teacher preparation programs to prepare teacher candidates in ways that make full participation of students with disabilities in regular education classrooms a reality.
\end{abstract}

\section{Keywords:}

Pre-service teachers, Inclusion, Special Education, Teacher Preparation Program

JEL Classification: 124 